\title{
Stem Cell Heterogeneity of Mononucleated Cells from Murine Peripheral Blood: Molecular Analysis
}

\author{
Muhammad Dain Yazid, ${ }^{1}$ Shahrul Hisham Zainal Ariffin, ${ }^{1}$ Sahidan Senafi, ${ }^{1}$ \\ Zaidah Zainal Ariffin, ${ }^{2}$ and Rohaya Megat Abdul Wahab ${ }^{3}$ \\ ${ }^{1}$ Faculty of Science and Technology, Universiti Kebangsaan Malaysia, Selangor, \\ 43600 Bangi, Malaysia \\ ${ }^{2}$ Department of Microbiology, Faculty of Applied Science, Universiti Teknologi MARA, \\ Selangor, 40450 Shah Alam, Malaysia \\ ${ }^{3}$ Faculty of Dentistry, Universiti Kebangsaan Malaysia, Kuala Lumpur Campus, \\ 50300 Kuala Lumpur, Malaysia
}

Received 13 September 2011; Accepted 18 October 2011

Academic Editors: A. Favaretto and C. Hosing

The main purpose of this paper was to determine the heterogeneity of primary isolated mononucleated cells that originated from the peripheral blood system by observing molecular markers. The isolated cells were cultured in complete medium for 4 to 7 days prior to the separation of different cell types, that is, adherent and suspension. Following a total culture time of 14 days, adherent cells activated the Cd105 gene while suspension cells activated the Sca-1 gene. Both progenitor markers, Cbfa-1 and Ostf-1, were inactivated in both suspension and adherent cells after 14-day culture compared to cells cultured 3 days in designated differentiation medium. In conclusion, molecular analyses showed that primary mononucleated cells are heterogeneous, consisting of hematopoietic stem cells (suspension) and mesenchymal stem cells (adherent) while both cells contained no progenitor cells.

KEYWORDS: mononucleated cells, adherent cells, suspension cells, hematopoietic stem cells, mesenchymal stem cells 


\section{INTRODUCTION}

Blood is a life-maintaining fluid that circulates through the body, carrying red blood cells (1.091$1.096 \mathrm{~g} / \mathrm{mL})$, white blood cells $(1.069-1.073 \mathrm{~g} / \mathrm{mL})$, and platelets $(1.025 \mathrm{~g} / \mathrm{mL})$ [1]. Each component has a different density and migrates according to the gradient of its density. Blood separation using FicollPaque Plus (GE Healthcare, USA), based on the principal of density gradient centrifugation, results in a heterogenic layer of mononucleated cells that consists of lymphocytes, monocytes, and platelets. About $95 \%$ of the isolated mononucleated cells are lymphocytes, and the average lifespans of lymphocytes, monocytes, and platelets are 2-3 days, 5-7 days, and 3-5 days, respectively [2]. These cells are critical and important components in the immune system, which fights infection and defends against intruders. A small fraction of peripheral blood cell populations consist of stem cells, that is, hematopoietic stem cells and mesenchymal stem cells.

Murine hematopoietic stem cells are primarily found in the bone marrow at a frequency of $1 / 10,000$ to 1/1,000,000 cells [3]. These hematopoietic stem cells are mobilized into the circulatory system and thus can be found in peripheral blood. This physiological phenomenon is important for maintaining a fixed number of hematopoietic stem cells in the bone marrow [4]. Hematopoietic stem cells can be found morphologically and proliferate in culture among ordinary white blood cells. It is difficult to differentiate the cells based on morphology alone; thus, other approaches have been used that serve to identify hematopoietic stem cells. One technique, used especially for mouse hematopoietic stem cells, uses surface markers, such as Sca1, Thy-1, Cd38, and c-kit [5]. Sca-1 was the first stem cell surface marker that was used as a marker for hematopoietic stem cells in haplo Ly-6 mice. It is an $18-\mathrm{kDa}$ phosphatidylinositol-anchored protein that is a member of the lymphocyte antigen 6 (Ly-6) family [6]. Sca-1 expression varies in hematopoietic stem cells and plays an important role during proliferation [7].

Mesenchymal stem cells primarily originate from the bone marrow. However, they can also be isolated from other sources, including compact bone, adipose tissue, cord blood, peripheral blood, fallopian tube, and fetal liver and lung [8]. However, the existence of these cells in adult blood [9] and umbilical cord blood [10] is controversial. Mesenchymal stem cells from these sources were found in heterogeneous mixtures contaminated with other progenitor cells [11]. Mesenchymal stem cells have the ability to proliferate in culture while retaining their growth and multilineage potential. The properties of mesenchymal stem cells make them potential candidates for cellular therapy, namely, the ability to migrate to sites of injury in animals when systemically transplanted. Mesenchymal stem cells are identified by the expression of specific markers such as $C d 73, C d 90$, and $C d 105$ [12]. Cd105, together with $C d 73$ and Stro-1, have been used to detect mesenchymal stem cells that were migrating to the site of acute myocardial infarction [13] and osteoarthritic synovial membranes [12].

In these studies, the existence of progenitor cells has to be determined for every isolates to ensure that determination of isolated stem cells will not be compromised. Progenitor cell is defined by cells that are able to divide and differentiate into one cell lineage only whereas stem cells is define by cells that are able to divide for indefinite periods of time and with the ability to differentiate into a variety of cell lineages [14-16].

Most research involving cell differentiation requires stem cells, which have the unique ability to selfrenew and differentiate into many cell types [17]. Mesenchymal and hematopoietic stem cells are widely used by researchers, especially in the field of cellular therapeutics. Nevertheless, most of these isolated cells are adherent and found in a heterogeneous mixture. Therefore, this study was undertaken to prove that both adherent and suspension cells can be isolated from primary mononucleated cells. In this study, we also showed that stem cells not only exist as adherent but also as suspension form. Furthermore, we are able to determine that adherent cells are mesenchymal stem cells whereas suspension cells are hematopoietic stem cells. In addition, the homogenous mixture can be separated accordingly, and it contains a homogenous stem cell population, which can be used as an alternative source in cellular therapy. 


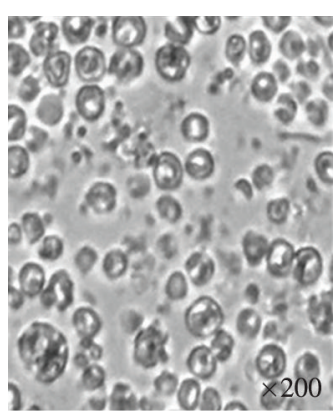

(a)

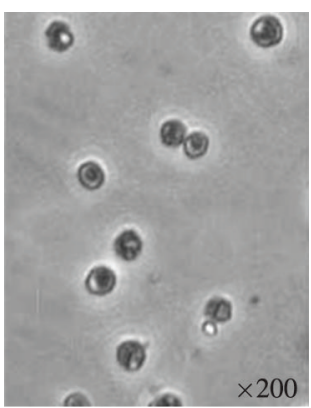

(b)

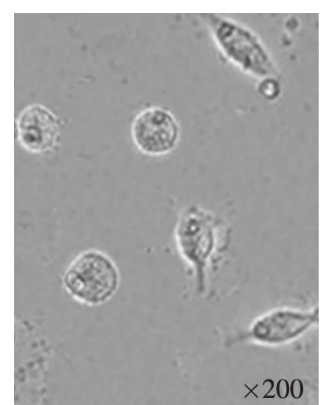

(c)

FIGURE 1: Morphology of mononucleated cells. Freshly isolated primary mononucleated cells (a). Both suspension mononucleated cells (b) and adherent mononucleated cells (c) were morphologically homoge-nous after 14 days in culture in complete medium (×200 magnification).

\section{RESULTS AND DISCUSSION}

\subsection{Isolation of Mononucleated Cells}

The isolation of mononucleated cells was based on the different density of each component in the blood and was separated using a synthetic polymer, Ficoll-Paque Plus. Ficoll is widely used to enrich and fractionate mononucleated cells from whole-blood samples. Whole blood was centrifuged and separated into 4 layers by gradient density. The mononucleated layer consisted of lymphocytes, monocytes, and platelets. After washing twice with PBS, 95\% of the mononucleated cells consisted of lymphocytes. Thus, these cells need to be maintained in complete medium for 14 days to allow most of the differentiated and progenitor cells to die due to a shorter lifespan $[2,18]$.

Figure 1(a) shows the various types of cells morphologically identified in freshly isolated primary mononucleated cells. After 7 days of culture in complete medium, two different types of cells were formed-adherent and suspension. The adherent cells were attached and expanded in cell culture dishes, while the suspension cells were transferred into another dish (Figure 1). Most of the suspension cells had one round nucleus (Figure 1(b)) whereas the adherent mononucleated cells had a long and thin body, similar to fibroblast-like cells (Figure 1(c)). Both mononucleated cells were cultured for an additional 7 days, for a total of 14 days, to allow proliferation prior to the enrichment and selection of the cells for subsequent analysis. Because the cells were not morphologically identified, they were subjected for further analysis using mouse-specific stem cell surface markers.

\subsection{Molecular Analysis}

The cells were cultured for 14 days, and total RNA was extracted using a standard protocol. The cells were validated by RT-PCR using highly pure total RNA from both cell types. Previous studies have shown that there are several specific cell surface markers that can distinguish and help isolate mesenchymal and hematopoietic stem cells. The $C d 38, S c a-1$, and $c$-Kit genes have been proposed to be markers for mouse hematopoietic stem cells while $C d 105, C d 73$, and $C d 90$ are markers for mesenchymal stem cells [19-21]. In this study, we used the $S c a-1$ cell surface marker for hematopoietic stem cells and the $C d 105$ cell surface marker for mesenchymal stem cells to test molecular markers of hematopoietic and mesenchymal stem cells on both cell types.

The RT-PCR results show the presence of Sca-1 amplicons of $167 \mathrm{bp}$ in suspensions of mononucleated cells while Cd105 amplification was not observed (Figure 2(A)). Mouse stem cells can express Sca-1, which regulates hematopoietic stem cell self-renewal and the development of specific progenitor 
(A)
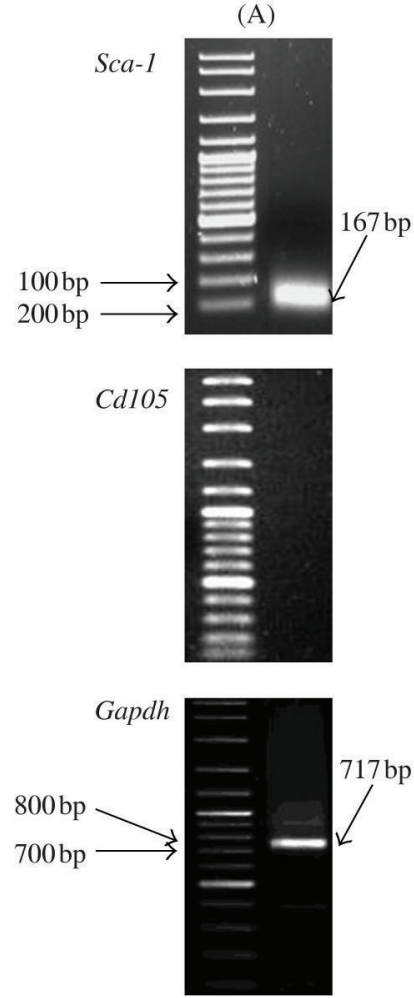

(B)
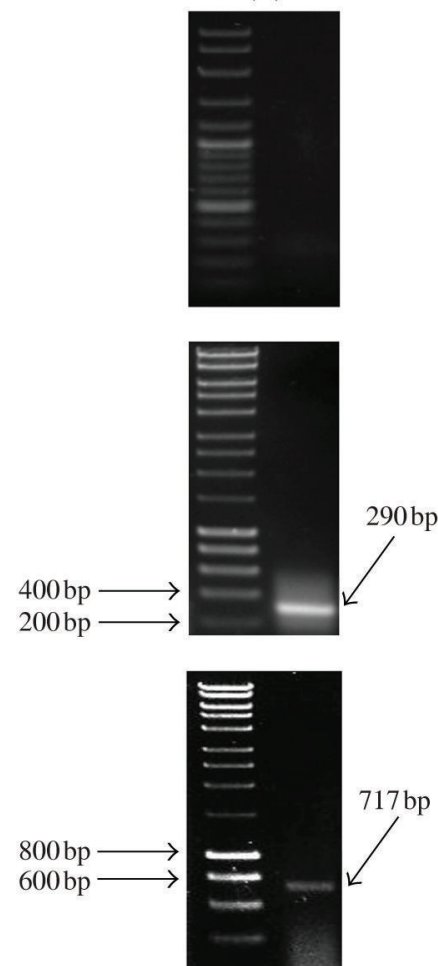

FIGURE 2: Activation of stem cell markers and housekeeping gene in suspension and adherent mononucleated cells. Activation of the hematopoietic stem cell marker (Sca-1), mesenchymal stem cell marker (Cd105), and housekeeping gene (Gapdh) in suspension mononucleated cell populations (A) and adherent mononucleated cell populations (B). Only Sca-1 was found to be activated in suspension cells, while only Cd105 was activated in adherent cells Gapdh, the housekeeping gene and positive control, was active in both types of mononucleated cells.

populations, such as blood cells [22]. Therefore, the expression of Sca-1, and lack of Cd105, reveals that mononucleated cells in suspension consist of hematopoietic stem cells and not mesenchymal stem cells.

Cd105 amplicons of $290 \mathrm{bp}$ were detected in adherent mononucleated cells (Figure 2(B)). However, there was no amplification of the $S \mathrm{Ca}-1$ gene. The expression of $\mathrm{Cd} 105$ represents a specific phenotype for mesenchymal stem cells. Cd105, or Endoglin, is a 90-kDa type I transmembrane glycoprotein that is part of the TGF beta receptor complex and has been found in endothelial cells and activated fibroblast cells [6]. The activation of Sca- 1 only in suspensions of mononucleated cells and the activation of $\mathrm{Cd} 105$ solely in adherent mononucleated cells indicate that mononucleated cell suspensions contain hematopoietic stem cells whereas the adherent mononucleated cell population contains mesenchymal stem cells.

Other approaches have been done in order to show that the suspension cells are hematopoietic stem cells via differentiation capacity through biochemical and morphology analyses. These indirectly showed that suspension cells are able to differentiate into mature cells, that is, osteoclast which originated from hematopoietic lineage. However, the suspension cells also showed the ability to differentiate into osteoblast, which is from mesenchymal lineage. This indicates that the cells are more primitive than hematopoietic stem cells $[2,23,24]$. However, this phenomenon could be implicated by transdifferentiation which occur in certain stem cells condition [25].

In this study, glyceraldehyde-3-phosphate dehydrogenase (Gapdh) was used as a positive control for each molecular experiment. Gapdh is a housekeeping gene commonly used in comparisons of gene expression data [26]. Several other genes can also act as positive controls, such as $\beta$-actin, $\beta_{2}$-microglobulin, 

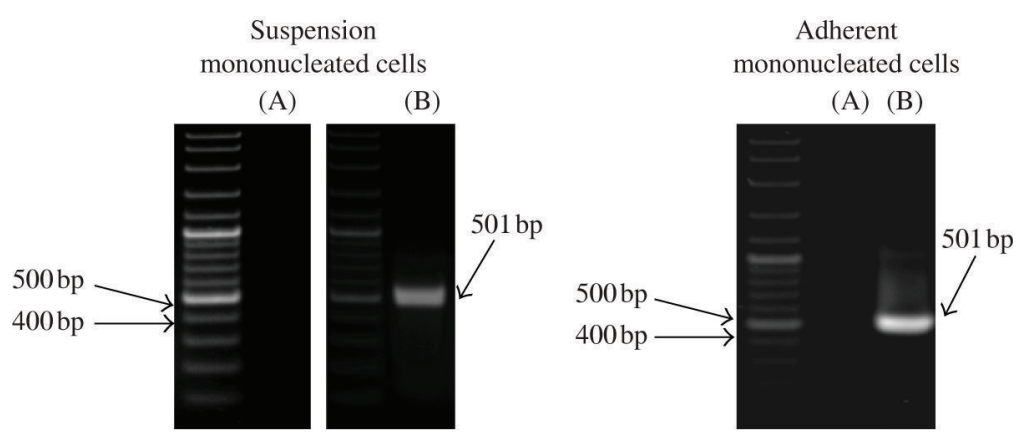

Cbfa-1

(A)

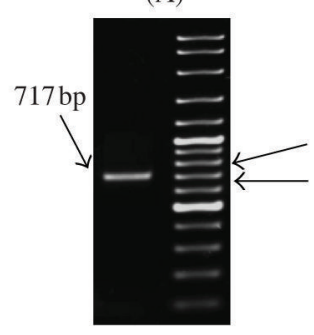

(B)

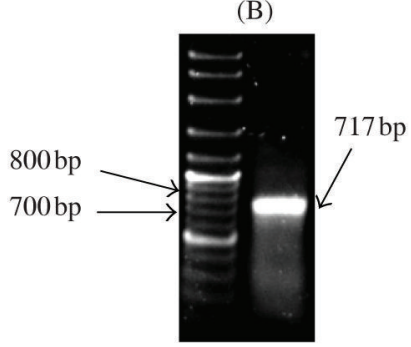

Gapdh

FIGURE 3: Active and inactive osteoblast progenitor markers and housekeeping gene in suspension and adherent mononucleated cells. (A) Cbfa-1 in undifferentiated mononucleated cells. (B) Cbfa-1 in mononucleated cells after 3 days in osteoblast differentiation medium. Gapdh is represented in suspension and adherent undifferentiated mononucleated cells (Left) and mononucleated cells after 3 days in osteoblast differentiation medium (Right). Cbfa-1 was not active in mononucleated cells but was active after 3 days in osteoblast differentiation medium. The positive control, Gapdh, was active before and after differentiation of mononucleated cells into osteoblasts.

cyclooxygenase 1, hypoxanthine phosphoribosyl-transferase, porphobilinogendeaminase, and transferrin receptors $[10,27,28]$. In this study, Gapdh was expressed in all cell lines, as shown by the 717-bp RT-PCR product in Figures 2, 3, and 4. Gapdh remained activated in both cell types and conditions, indicating that the cells are viable and undergo survival processes [29].

\subsection{Absence of Progenitor Cells in Mononucleated Cell Populations}

After cells in suspension and adherent population were analyzed for identity, the homogeneity of the cells was observed. Molecular analyses were done to make sure that the populations were not contaminated with progenitor cells. Consistent with previous studies, osteoblast progenitor cells were found in blood, in addition to hematopoietic progenitor cells [4]. Thus, osteoblast and osteoclast progenitor markers, $\mathrm{Cbfa-1}$ and Ostf-1, respectively, were analyzed. Using these markers, the RT-PCR did not show any amplicons in undifferentiated suspension or adherent mononucleated cells (Figure 3(A)) while Cbfa-1 amplicons of 501 bp in osteoblast differentiated suspension and adherent mononucleated cells were observed (Figure 3(B)).

Figure 3 shows that the $C b f a-1$ gene was inactive in suspension and adherent mononucleated cell populations. The $C b f a-1$ gene was activated only after both cells were differentiated into osteoblasts for 3 days. Suspension and adherent mononucleated cells that were exposed to specific osteoblast and osteoclast differentiation factors for 3 days acted as positive controls. Cbfa-1, also known as Pebp $2 \alpha \mathrm{A}$ (polyome enhancer binding protein), is a DNA binding protein that binds to the Cbfa- $\beta$ complex from the runtdomain family. This runt-domain family member binds and regulates the transcription of genes in specific 

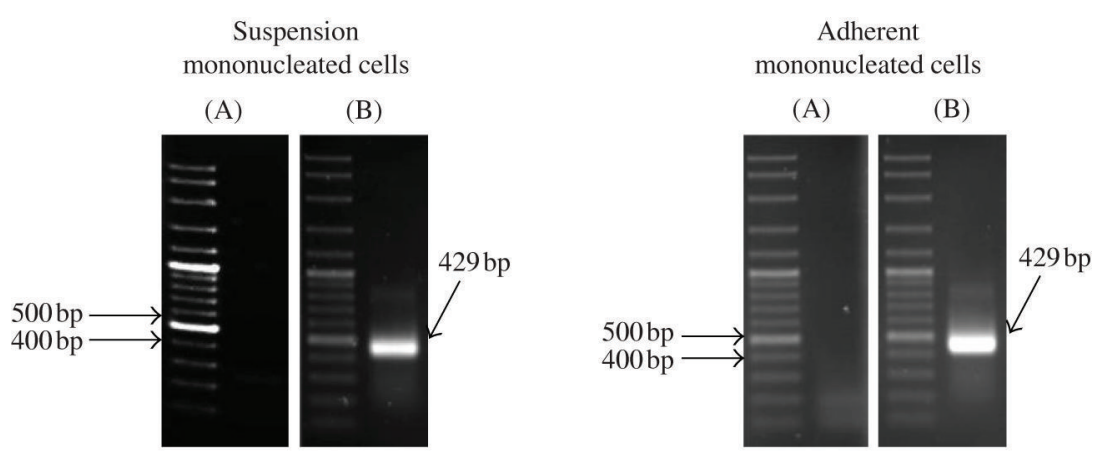

Ostf-1

(A)

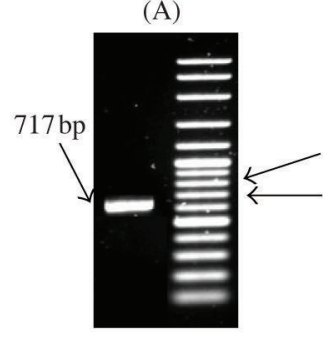

(B)

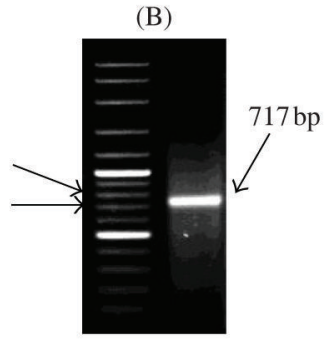

Gapdh

FIGURE 4: Active and inactive osteoclast progenitor markers and housekeeping gene in suspension and adherent mononucleated cells. (A) Ostf-1 in undifferentiated mononucleated cells. (B) Ostf-1 in mononucleated cells after 3 days in osteoclast differentiation medium. Gapdh is represented in suspension and adherent undifferentiated mononucleated cells (Left) and mononucleated cells after 3 days in osteoclast differentiation medium (Right). Ostf-1 was not active in mononucleated cells but was active after 3 days in osteoclast differentiation medium. The positive control, Gapdh, was active before and after differentiation of mononucleated cells into osteoclasts.

tissues that have a unique Cbfa-1 consensus sequence [30]. According to Ducy et al., forced expression of Cbfa-1 in nonosteoblastic cells induces the expression of the principal osteoblast specific genes, and thus, differentiates the cells into osteoblast cells $[31,32]$. In this study, osteoblast progenitor cells were not found in mononucleated cells cultured for 14 days.

Figure 4 shows the activation profile of the $O s t f-1$ gene in suspension and adherent mononucleated cells before and after differentiation. RT-PCR did not show any Ostf-1 amplicons in undifferentiated suspension or adherent mononucleated cells (Figure 4(A)) while it was present in osteoclast differentiated suspension and adherent mononucleated cells (Figure 4(B)). These results show that Ostf- 1 was inactive in both mononucleated cells but activated after 3 days in osteoclast differentiation medium. The 28-kDa protein expressed by the Ostf-1 gene, OSF-1 (osteoclast stimulating factor-1), or M-CSF protein (macrophagecolony stimulating factor) [33], binds to the colony-stimulating factor 1 receptor on osteoclast precursor cells and is involved in osteoclast differentiation [34]. In this study, both suspension and adherent mononucleated cell populations showed an absence of osteoclast progenitor cells.

\section{CONCLUSION}

In conclusion, isolated mononucleated primary cells consist of hematopoietic stem cells (in suspension form) and mesenchymal stem cells (in adherent form). The adherent and suspension mononucleated populations were not "contaminated" with osteoblast and osteoclast progenitors, indicating that the isolated cells were homogenous. 
TABLE 1: Primer sequences used in RT-PCR analyses.

\begin{tabular}{|c|c|c|c|}
\hline Gene & Primer & Sequence & Expected size (bp) \\
\hline \multirow{2}{*}{ Gapdh } & Forward & 5'CAACGGCACAGTCAAGG3' & \multirow{2}{*}{717} \\
\hline & Reverse & 5'AAGGTGGAAGAGTGGGAGT3' & \\
\hline \multirow{2}{*}{ Sca-1 } & Forward & 5'GGCAGGGTCCCAGACTCCAT3' & \multirow{2}{*}{167} \\
\hline & Reverse & 5'GTGTTGGTGGTGGGCTAC3' & \\
\hline \multirow{2}{*}{ Cd105 } & Forward & 5'GCTCCCTCTGGCTGTTG3' & \multirow{2}{*}{290} \\
\hline & Reverse & 5'TTACACTGAGGACCAGAAGC3' & \\
\hline \multirow{2}{*}{ Ostf-1 } & Forward & 5'GAACCCAGAACTCCAGAT3' & \multirow{2}{*}{501} \\
\hline & Reverse & 5'TGTCCTCGCACCTTTT3' & \\
\hline \multirow{2}{*}{ Cbfa-1 } & Forward & 5'ACTATGGCGTCAAACAGC3' & \multirow{2}{*}{429} \\
\hline & Reverse & 5'AGCACGGAGCACAGGA3' & \\
\hline
\end{tabular}

\section{MATERIALS AND METHODS}

\subsection{Isolation of Mononucleated Cells}

Blood samples were obtained from healthy 4- to 6-week-old ICR strain mice. The mononucleated cells were isolated by density gradient centrifugation with Ficoll-Paque Plus (G.E. Healthcare, USA). Briefly, $1 \mathrm{~mL}$ blood samples were diluted 1:3 with Hanks' Balanced Salt Solution (HBSS; Sigma, USA) and transferred into $1.5 \mathrm{~mL}$ Ficoll-Paque Plus, followed by centrifugation at $400 \times \mathrm{g}$ for $30 \mathrm{~min}$ at room temperature. Differential migration during centrifugation results in the formation of layers consisting of granulocytes and erythrocytes at the bottom, polymorphonuclear cells in the Ficoll-Paque layer, mononuclear cells above that, and plasma at the top. The mononucleated cells were transferred into a fresh new tube and washed twice with phosphate-buffered saline (PBS; Sigma, USA). The mononucleated cells were cultured in complete medium consisting of $\alpha$-Minimal Essential Medium ( $\alpha$-MEM; Invitrogen, USA) supplemented with $10 \%(\mathrm{v} / \mathrm{v}$ ) newborn calf serum (NBCS; Invitrogen, USA) and 2\% (v/v) penicillin-streptomycin solution (Invitrogen, USA).

\subsection{Cells Culture and Separation of Adherent and Suspension Cells}

Mononucleated cells were seeded in 6-well plates for about 14 days. Cultures were maintained at $37^{\circ} \mathrm{C}$ in a humidified atmosphere containing $5 \% \mathrm{CO}_{2}$. Starting from day 1, nonadhered cells were transferred into a new well while the attached cells were left for further culture. This routine was repeated daily for about 4 to 7 days until homogenous cells for both adherent and suspension cells were formed. Then both adherent and suspension cells were maintained for an additional 7 days in complete medium, which was exchanged twice, for a total of 14 days in medium selection. Next, both cell populations were subjected to molecular analyses.

\subsection{Molecular Analysis Using RT-PCR}

Total RNA was isolated from both types of cells using TRI-Reagent (Sigma, USA) according to the manufacturer's instructions. Absorbances at $260 \mathrm{~nm}$ and $280 \mathrm{~nm}$ were used to measure the RNA purity; an A260 : A280 ratio of 1.8-2.0 was acceptable. Reverse transcriptase polymerase chain reaction (RT-PCR) was performed with AMV reverse transcriptase and T $f$ DNA polymerase in the Access RT-PCR System (Promega Corporation, USA). The primers were designed using Primer Premier 5.0 based on the sequences of Sca-1 (accession number: NM 007802), Cd105 (accession number: NM 001146348), Gapdh (accession number: NM 008084), Ostf-1 (accession number: NM 017375), and Cbfa-1 (accession number: NM 001145920) obtained from NCBI (Table 1). 
The RT-PCR was carried out in a Mastercyler Gradient (Eppendorf, Germany). Reverse transcription (RT) was performed using a program of $45^{\circ} \mathrm{C}$ for $45 \mathrm{~min}$ and predenaturation at $94^{\circ} \mathrm{C}$ for $2 \mathrm{~min}$. The amplification program was as follows: 40 cycles of three-step amplification (denaturation, $94^{\circ} \mathrm{C}$ for $30 \mathrm{~s}$; annealing, $56^{\circ} \mathrm{C}(\mathrm{Cd} 38), 57^{\circ} \mathrm{C}(\mathrm{Cd} 73), 61^{\circ} \mathrm{C}(\mathrm{Cd} 105), 63^{\circ} \mathrm{C}(\mathrm{Sca}-1), 63^{\circ} \mathrm{C}(\mathrm{Cbfa}-1), 56^{\circ} \mathrm{C}($ Ostf- 1$)$ for $60 \mathrm{~s}$, and extension, $68^{\circ} \mathrm{C}$ for $60 \mathrm{~s}$ ). A final extension step at $68^{\circ} \mathrm{C}$ for $7 \mathrm{~min}$ was then carried out. Detection of the PCR amplicons was performed by size fractionation by $1 \%(\mathrm{w} / \mathrm{v})$ agarose gel electrophoresis and the amplicon sizes were approximated by a 100-bp DNA marker. All amplified products were subjected to DNA sequencing and verified using the BLASTN program from NCBI.

\subsection{Differentiation of Mononucleated Cells in Suspension}

About $1 \times 10^{5}$ mononucleated cells in suspension were differentiated into osteoblasts and osteoclasts using differentiation factors. For osteoblast differentiation, $50 \mathrm{ng} / \mathrm{mL}$ ascorbic acid (Sigma, USA) and $10 \mathrm{mM} \beta$-glycerophosphate (Sigma, USA) were added into complete medium while $10 \mathrm{ng} / \mathrm{mL}$ RANKL (Peprotech, USA) and $5 \mathrm{ng} / \mathrm{mL}$ M-CSF (Peprotech, USA) were added into complete medium for osteoclast differentiation. The cells were cultured in their respective differentiation media for 3 days, at which point, total RNA was isolated for molecular analysis by RT-PCR.

\section{ACKNOWLEDGMENTS}

This research project was funded by Grant UKM-DD-03-FRGS0030-2010 and UKM/1/2011/SG/UKM/ 02/13 from the Ministry of Higher Education of Malaysia, UKM-OUP-KPB-33-170/2010 and UKM-GUP2011-093 from Universiti Kebangsaan Malaysia, and 09-05-MGI-GMB002 from the Ministry of Science, Technology and Innovation of Malaysia.

\section{REFERENCES}

[1] R. S. Schwartz, S. Musto, M. E. Fabry, and R. L. Nagel, "Two distinct pathways mediate the formation of intermediate density cells and hyperdense cells from normal density sickle red blood cells," Blood, vol. 92, no. 12, pp. 4844-4855, 1998.

[2] S. H. Zainal Ariffin, I. Z. Zainol Abidin, M. D. Yazid, and R. Megat Abdul Wahab, "Differentiation analyses of adult suspension mononucleated peripheral blood cells of Mus musculus," Cell Communication and Signaling, vol. 8, article 29, 2010.

[3] T. L. Holyoake, F. E. Nicolini, and C. J. Eaves, "Functional differences between transplantable human hematopoietic stem cells from fetal liver, cord blood, and adult marrow," Experimental Hematology, vol. 27, no. 9, pp. 1418-1427, 1999.

[4] R. M. Lemoli and A. D'Addio, "Hematopoietic stem cell mobilization," Haematologica, vol. 93, no. 3, pp. 321$324,2008$.

[5] I. L. Weissman, "Stem cells: units of development, units of regeneration, and units in evolution," Cell, vol. 100, no. 1, pp. 157-168, 2000.

[6] C. Y. Ito, C. Y. J. Li, A. Bernstein, J. E. Dick, and W. L. Stanford, "Hematopoietic stem cell and progenitor defects in Sca-1/Ly-6A-null mice," Blood, vol. 101, no. 2, pp. 517-523, 2003.

[7] X. Wang, Q. Hu, Y. Nakamura et al., "The role of the Sca-1 ${ }^{+} / \mathrm{CD} 31-$ cardiac progenitor cell population in postinfarction left ventricular remodeling," Stem Cells, vol. 24, no. 7, pp. 1779-1788, 2006.

[8] J. H. Sung, H. M. Yang, J. B. Park et al., "Isolation and characterization of mouse mesenchymal stem cells," Transplantation Proceedings, vol. 40, no. 8, pp. 2649-2654, 2008.

[9] I. Kassis, L. Zangi, R. Rivkin et al., "Isolation of mesenchymal stem cells from G-CSF-mobilized human peripheral blood using fibrin microbeads," Bone Marrow Transplantation, vol. 37, no. 10, pp. 967-976, 2006.

[10] P. D. Lee, R. Sladek, C. M. T. Greenwood, and T. J. Hudson, "Control genes and variability: absence of ubiquitous reference transcripts in diverse mammalian expression studies," Genome Research, vol. 12, no. 2, pp. 292-297, 2002. 
[11] M. Neagu, E. Suciu, V. Ordodi, and V. Paunescu, "Human mesenchymal stem cells as basic tools for tissue engineering: isolation and culture," Romanian Journal of Biophysics, vol. 15, pp. 29-34, 2005.

[12] T. Hermida-Gómez, I. Fuentes-Boquete, M. J. Gimeno-Longas et al., "Quantification of cells expressing mesenchymal stem cell markers in healthy and osteoarthritic synovial membranes," Journal of Rheumatology, vol. 38, no. 2, pp. 339-349, 2011.

[13] K. Kollar, M. M. Cook, K. Atkinson, and G. Brooke, "Molecular mechanisms involved in mesenchymal stem cell migration to the site of acute myocardial infarction," International Journal of Cell Biology, vol. 2009, Article ID 904682, 8 pages, 2009.

[14] S. H. Zainal Ariffin, Y. Zulham, I. Z. Zainol Abidin, R. M. Abdul Wahab, and Z. Zainal Ariffin, "Cellular and molecular changes in orthodontic tooth movement," TheScientificWorldJOURNAL, vol. 11, no. 1, pp. 1-16, 2011.

[15] Z. A. Shahrul Hisham, M. A. W. Rohaya, Z. A. Intan Zarina, S. Sahidan, M. M. Nor, and Z. A. dan Zaidah, "Review: Sel Stem dalam perkembangan darah," Sains Malaysiana, vol. 34, pp. 1-17, 2005.

[16] S. H. Z. Ariffin, R. M. A. Wahab, I. Ismail, N. M. Mahadi, and Z. Z. Ariffin, "Stem cells, cytokines and their receptors," Asia-Pacific Journal of Molecular Biology and Biotechnology, vol. 13, no. 1, pp. 1-13, 2005.

[17] Q. Shen, S. K. Goderie, L. Jin et al., "Endothelial cells stimulate self-renewal and expand neurogenesis of neural stem cells," Science, vol. 304, no. 5675, pp. 1338-1340, 2004.

[18] Z. A. I. Zarina, Z. A. S. Hisham, M. A. W. Rohaya, S. Sahidan, and Z. A. Zaidah, "Osteoclast and osteoblast development of Mus musculus haemopoietic mononucleated cells," Journal of Biological Sciences, vol. 8, no. 3, pp. 506-516, 2008.

[19] M. F. Pittenger, A. M. Mackay, S. C. Beck et al., "Multilineage potential of adult human mesenchymal stem cells," Science, vol. 284, no. 5411, pp. 143-147, 1999.

[20] E. H. Javazon, J. Tebbets, and K. Beggs, "Isolation, expansion, and characterization of murine adult bone marrow derived, mesenchymal stem cells," Blood, vol. 102, pp. 180B-181B, 2003.

[21] A. Peister, J. A. Mellad, B. L. Larson, B. M. Hall, L. F. Gibson, and D. J. Prockop, "Adult stem cells from bone marrow (MSCs) isolated from different strains of inbred mice vary in surface epitopes, rates of proliferation, and differentiation potential," Blood, vol. 103, no. 5, pp. 1662-1668, 2004.

[22] H. C. Lee, "Structure and enzymatic functions of human CD38," Molecular Medicine, vol. 12, no. 11-12, pp. 317-323, 2006.

[23] M. D. Yazid, S. H.Z. Ariffin, S. Senafi, M. A. Razak, and R. M.A. Wahab, "Determination of the differentiation capacities of murines' primary mononucleated cells and MC3T3-E1 cells," Cancer Cell International, vol. 10, article 42, 2010.

[24] I. Z. Z. Abidin, S. H. Z. Ariffin, Z. Z. Ariffin, and R. M. A. Wahab, "Keupayaan pembezaan tiga Jenis sel primitif daripada hasil perbezaan tempoh proliferasi darah mencit," Sains Malaysiana, vol. 39, no. 2, pp. 305-313, 2010.

[25] L. Song and R. S. Tuan, "Transdifferentiation potential of human mesenchymal stem cells derived from bone marrow," FASEB Journal, vol. 18, no. 9, pp. 980-982, 2004.

[26] R. D. Barber, D. W. Harmer, R. A. Coleman, and B. J. Clark, "GAPDH as a housekeeping gene: analysis of GAPDH mRNA expression in a panel of 72 human tissues," Physiological Genomics, vol. 21, pp. 389-395, 2005.

[27] K. Gorzelniak, J. Janke, S. Engeli, and A. M. Sharma, "Validation of endogenous controls for gene expression studies in human adipocytes and preadipocytes," Hormone and Metabolic Research, vol. 33, no. 10, pp. 625-627, 2001.

[28] O. Thellin, W. Zorzi, B. Lakaye et al., "Housekeeping genes as internal standards: use and limits," Journal of Biotechnology, vol. 75, no. 2-3, pp. 291-295, 1999.

[29] A. Tarze, A. Deniaud, M. Le Bras et al., "GAPDH, a novel regulator of the pro-apoptotic mitochondrial membrane permeabilization," Oncogene, vol. 26, no. 18, pp. 2606-2620, 2007.

[30] I. Majore, P. Moretti, R. Hass, and C. Kasper, "Identification of subpopulation in mesenchymal stem cell-like cultures from human umbilical cord," Cell Communication and Signaling, vol. 7, article 6, 2009.

[31] P. Ducy, R. Zhang, V. Geoffroy, A. L. Ridall, and G. Karsenty, "Osf2/Cbfa1: a transcriptional activator of osteoblast differentiation," Cell, vol. 89, no. 5, pp. 747-754, 1997.

[32] E. Fonsatti and M. Maio, "Highlights on endoglin (CD105): from basic findings towards clinical applications in human cancer," Journal of Translational Medicine, vol. 2, article no. 18, 2004. 
[33] M. Katebi, M. Soleimani, and B. N. Cronstein, “Adenosine a2A receptors play an active role in mouse bone marrow-derived mesenchymal stem cell development," Journal of Leukocyte Biology, vol. 85, no. 3, pp. 438-444, 2009.

[34] J. J. Westendorf and S. W. Hiebert, "Mammalian runt-domain proteins and their roles in hematopoiesis, osteogenesis, and leukemia," Journal of Cellular Biochemistry, vol. 76, no. 33, pp. 51-58, 1999.

\section{This article should be cited as follows:}

Muhammad Dain Yazid, Shahrul Hisham Zainal Ariffin, Sahidan Senafi, Zaidah Zainal Ariffin, and Rohaya Megat Abdul Wahab, "Stem Cell Heterogeneity of Mononucleated Cells from Murine Peripheral Blood: Molecular Analysis," TheScientificWorldJOURNAL, vol. 11, pp. 2150-2159, 2011. 


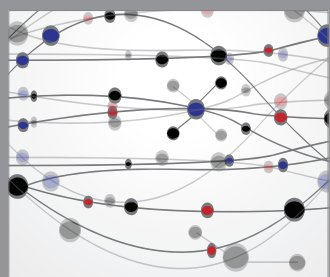

The Scientific World Journal
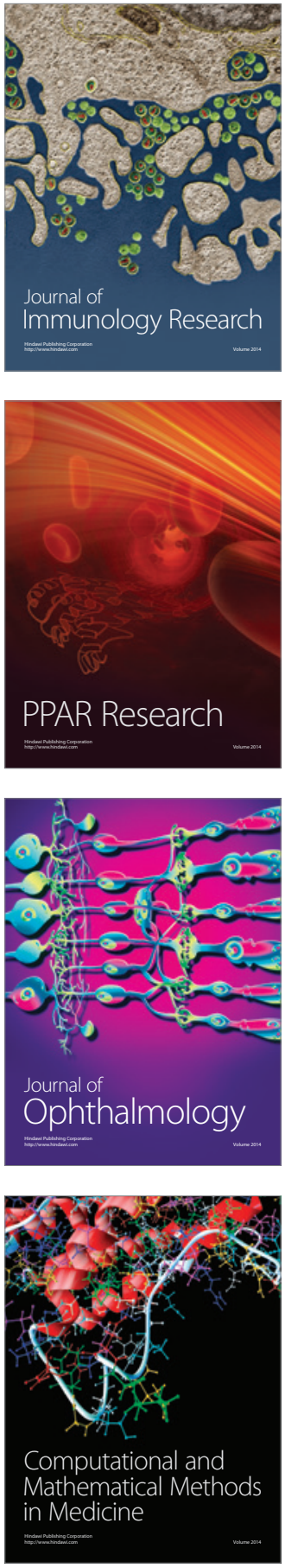

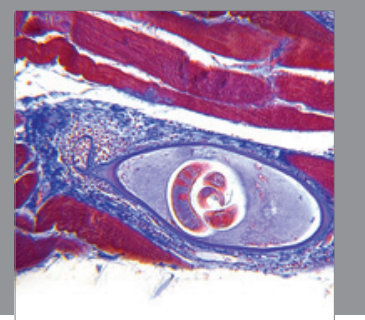

Gastroenterology

Research and Practice
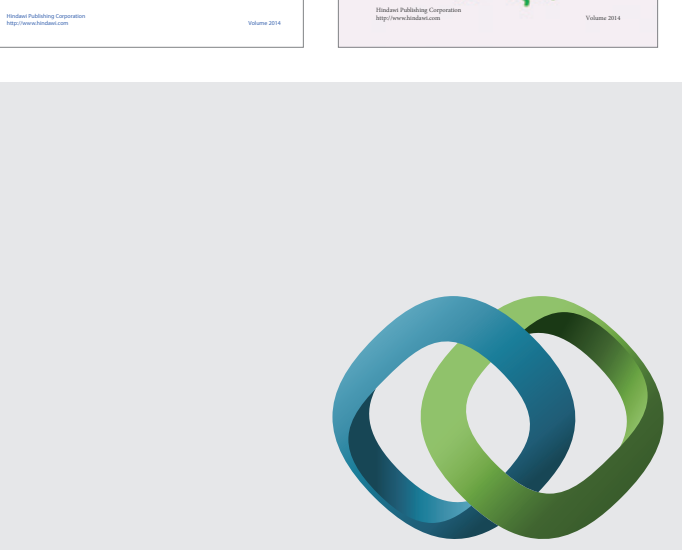

\section{Hindawi}

Submit your manuscripts at

http://www.hindawi.com
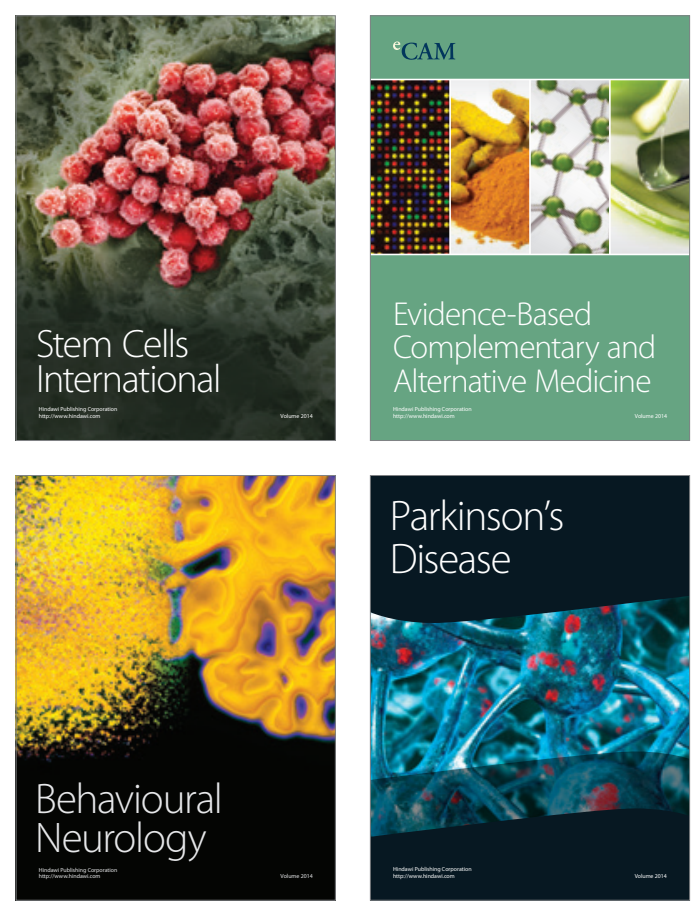

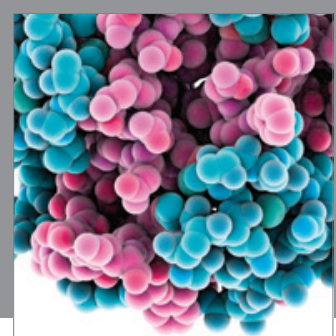

Journal of
Diabetes Research

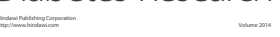

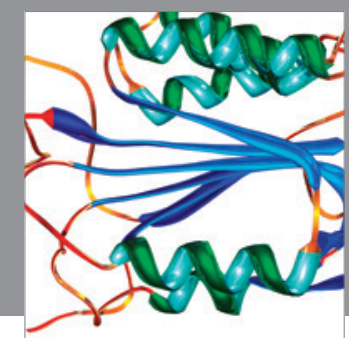

Disease Markers
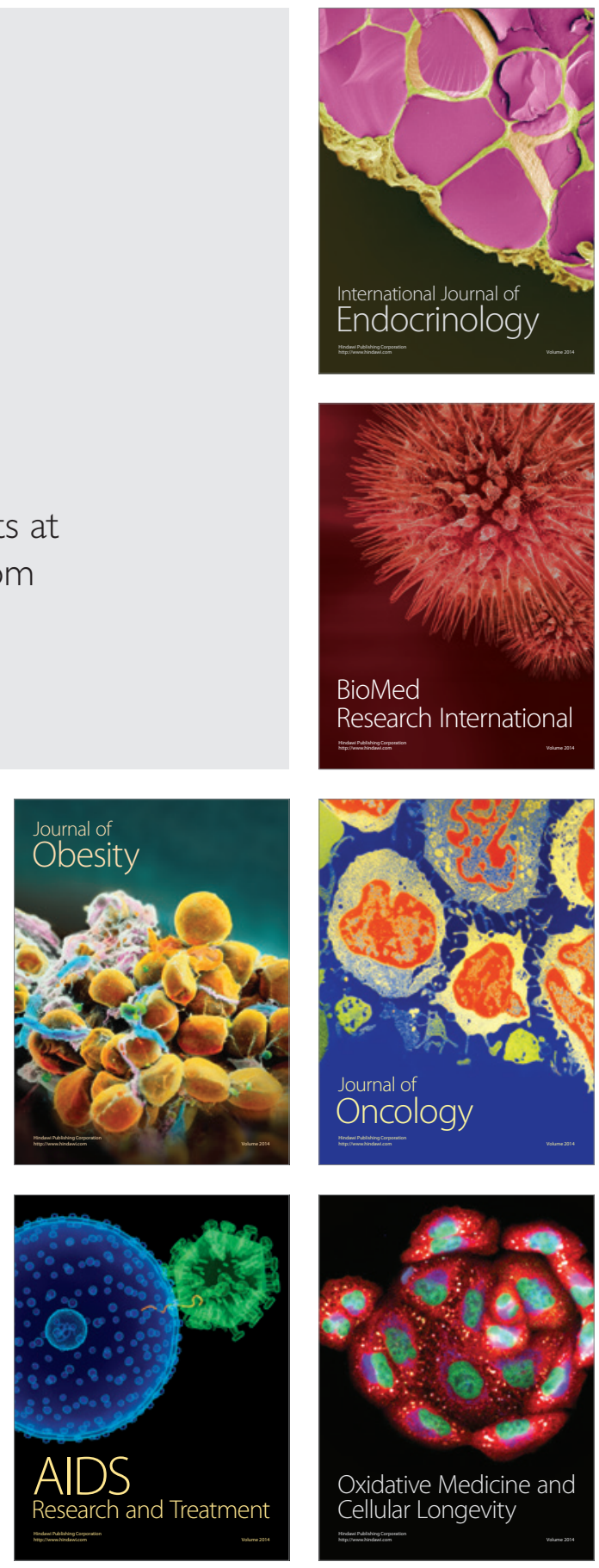